\title{
Pulmonary artery repair during robotic lung resection: narrative review and management
}

\author{
Pierre-Benoit Pagès ${ }^{1,2}$, Ivan Gutierrez ${ }^{1}$, Jean-Marc Baste ${ }^{3}$ \\ ${ }^{1}$ Department of Thoracic Surgery, CHU Dijon Bourgogne, Dijon, France; ${ }^{2}$ INSERM UMR 1231, CHU Dijon, University of Burgundy, Dijon, \\ France; ${ }^{3}$ Department of Thoracic Surgery, Hospital Charles Nicole, Rouen, France \\ Contributions: (I) Conception and design: PB Pagès, I Gutierrez; (II) Administrative support: PB Pagès, I Gutierrez; (III) Provision of study materials \\ or patients: PB Pagès, I Gutierrez; (IV) Collection and assembly of data: PB Pagès, I Gutierrez; (V) Data analysis and interpretation: PB Pagès, I \\ Gutierrez; (VI) Manuscript writing: All authors; (VII) Final approval of manuscript: All authors. \\ Correspondence to: Pierre-Benoit Pagès, MD, PhD. Department of Thoracic and Cardiovascular Surgery, CHU Dijon, Hôpital du Bocage, 14 rue \\ Gaffarel, BP 77908, 21079 Dijon, France. Email: pierrebenoit.pages@chu-dijon.fr.
}

\begin{abstract}
Minimally invasive surgery is currently the standard of care for the surgical management of early-stage lung cancer. The generalization of robotic and video-assisted thoracic surgery (VATS) for lung cancer resection, emphasize the problem of the management of major intraoperative complications. Here in, we report our experience regarding the management of major bleeding occurring during robotic lung cancer resection. We sought to define an appropriate approach to manage pulmonary artery injury (PAI) and to prevent the occurrence of vascular injury. The intraoperative management of these injuries is based on crisis scenario that must be repeated and prepared beforehand including the whole team of anesthesiologist and nurses, highlighting the role of team communication. Moreover, it emphasizes the function of the assistant who is close to the patient; he had to help the main surgeon to control the bleeding before the main surgeon can perform conversion thoracotomy if the vessel could not be repaired robotically. Moreover, we reported the different methods of prevention of vascular injuries that need to be taught. Prevention is based on surgical and case control simulation with the whole team in the operating room, training with robot simulators to improve technical aspects and preoperative planning using 3-dimensional imaging to investigate more precisely the disposition of the pulmonary arteries and veins.
\end{abstract}

Keywords: Vascular injury; simulation; prevention; robotic surgery; lung resection

Received: 23 June 2020; Accepted: 04 December 2020; Published: 20 January 2022.

doi: $10.21037 /$ jovs-20-147

View this article at: http://dx.doi.org/10.21037/jovs-20-147

\section{Introduction}

Nowadays, minimally invasive surgery appears to be the standard of care for early-stage lung cancer. In the last decade, the use of minimally invasive approaches such as video-assisted thoracic surgery (VATS) or robotic-assisted thoracic surgery (RATS) has expanded worldwide.

Despite the generalization of these techniques, VATS and RATS need to be performed in expert centers because of the risk of major intraoperative complications (1-4). Flores et al. were the first to describe a large series of VATS lobectomy in which 13 cases (1\%) had major intraoperative complications that led to unplanned major procedures such as pneumonectomy (1). More recently, the European Society of Thoracic Surgeons minimally invasive thoracic surgery interest group reported that $22 \%$ of in-hospital mortality was related to major intraoperative complications (3).

The literature reports a similar risk of vascular injury with the robotic approach, with rates ranging from $0.5 \%$ to $2.6 \%(1,4-9)$. In this context, vascular injury leads to a significant increase in in-hospital mortality, as reported recently by Cao et al. (10).

In this paper, we focus on strategies developed by our team to prevent and manage major intraoperative 


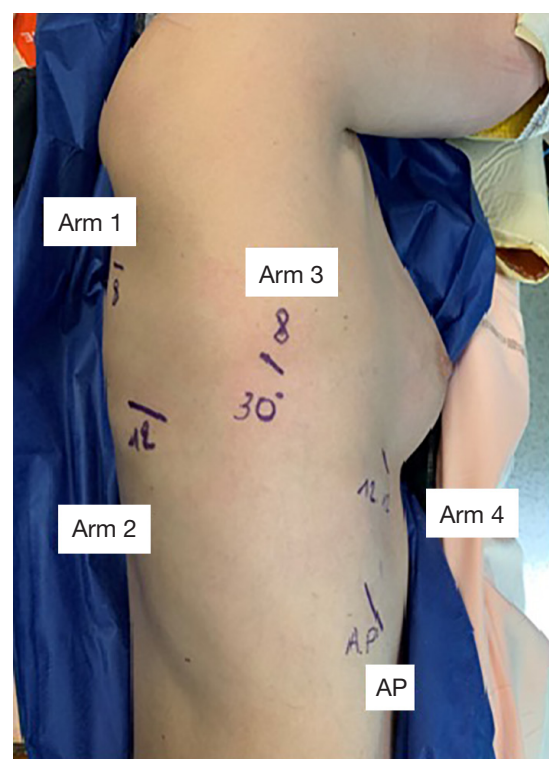

Figure 1 Port placement during RATS resection. Two $8 \mathrm{~mm}$ ports for the optic (Arm3) and for the exposure (Arm 1); and two $12 \mathrm{~mm}$ port for the staplers (Arm 2 and Arm 4). AP, assistant port; RATS, robotic-assisted thoracic surgery.

bleeding during robotic surgery. We present the following article in accordance with the Narrative Review reporting checklist (available at https://jovs.amegroups.com/article/ view/10.21037/jovs-20-147/rc).

\section{Usual port placement (Figure 1)}

First, an $8 \mathrm{~mm}$ port was placed just below the scapular spine in the $6^{\text {th }}$ intercostal space (Arm 3). The Airseal port was then placed in the $9^{\text {th }}$ intercostal space, on the anterior axillary line. Robotic arm port $1(8 \mathrm{~mm})$ was placed in the $6^{\text {th }}$ intercostal space on the posterior axillary line, arm port $2(12 \mathrm{~mm})$ was placed in the $8^{\text {th }}$ intercostal space on the posterior axillary line, and arm port $4(12 \mathrm{~mm})$ port was placed in the $6^{\text {th }}$ intercostal space on the anterior axillary line.

After docking the robot, a $30^{\circ}$ camera was introduced through the Arm 3. A tip-up forceps was inserted in arm port 1, a Cadiere grasper was inserted in arm 2 and a Maryland bipolar forceps was inserted in arm port 4 .

The surgical assistant was positioned in front of the patient with a long suction tip.

\section{Equipment preference cards}

(I) 3D high-definition camera ( $30^{\circ}$ lens);
(II) One cadiere forceps to retract tissue during the dissection of vessels and bronchus;

(III) One Maryland forceps connected to an additional ERBE $^{\odot}$ generator (ERBE, Limonest, France) for electrocoagulation, sectioning and to dissect and free the vessels and bronchus;

(IV) One tip-up forceps used to retract lung parenchyma (to better expose the surgical field) and to clamp the PA without applying too much pressure which could lead to additional injury;

(V) One large needle driver used to repair the PA.

The DaVinci Xi Surgical system (Intuitive surgical SAS, Montrouge, France) is placed perpendicular to the table. The patient position was that of conventional surgery, with the head placed close to the anesthesia station.

\section{Management of pulmonary artery injury (PAI)}

PAI is a rare but serious occurrence during minimally invasive thoracic surgery. In a 2019 publication that evaluated the occurrence of PAI during robotic lung resection, the incidence was found to be around $1.5 \%$ in high volume centers (10).

\section{Surgical management (Figure 2)}

The location of the PAI is the key to management, raising the question of whether is it possible to control the bleeding using a robotic approach. In other words: can the bleeding be controlled and can the upstream pulmonary artery (PA) be clamped? (Figure 2). In our experience, repairing the injury robotically is complex and is only feasible for surgeons with extensive experience in minimally invasive thoracic surgery, especially using the robotic approach and ideally in expert and high-volume centers that also possess highly-trained support teams (Table 1).

There are essentially two PAI scenarios during RATS lung resection: firstly, the injury is located on the main PA during upper lobectomy, or, secondly, the injury is located on the lower or middle lobe arteries or on the distal branches of any lobe.

The first step in both situations is to immediately control the bleeding with a sponge stick.

\section{Proximal PAI (Video 1, Figures 3,4)}

PAI mostly occurred during upper lobectomy or lymph node dissection. If the main PA was already encircled with a 


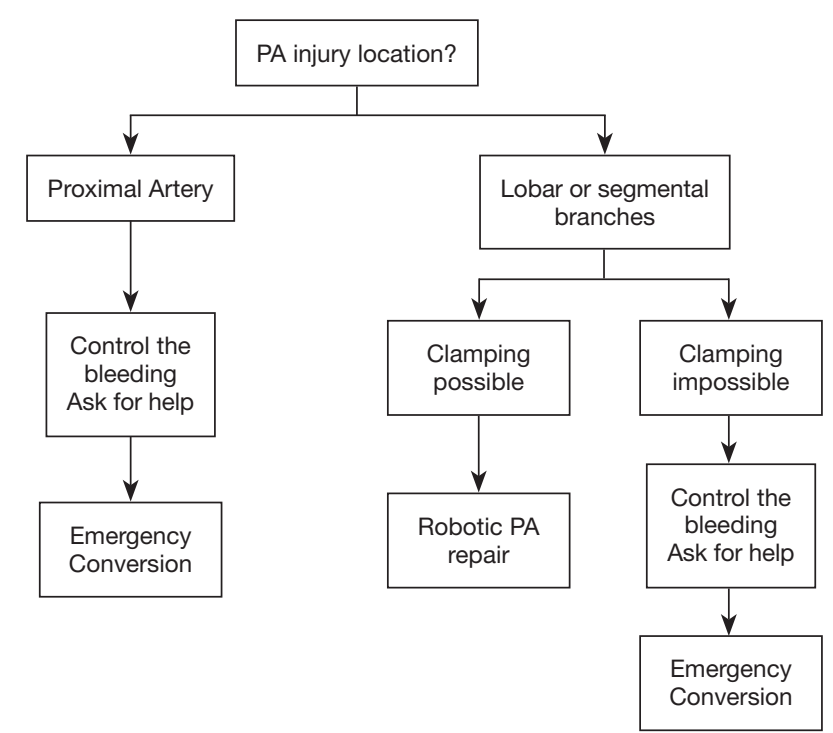

Figure 2 Decisional tree of the management of preoperative pulmonary artery injury.

Table 1 Dijon's University Hospital team experience of robotic pulmonary resection

\begin{tabular}{lcccc}
\hline & 2017 & 2018 & 2019 & $\begin{array}{c}2020 \text { until } \\
\text { 1st October }\end{array}$ \\
\hline $\begin{array}{l}\text { Number of pulmonary } \\
\text { resections }\end{array}$ & 60 & 65 & 80 & 72 \\
$\begin{array}{l}\text { Bilobectomy } \\
\text { Lobectomy }\end{array}$ & 0 & 1 & 2 & 1 \\
$\begin{array}{l}\text { Segmentectomy } \\
\text { Vascular injury }\end{array}$ & 55 & 47 & 50 & 39 \\
Robotic vascular repair & 0 & 0 & 2 & 32 \\
$\begin{array}{l}\text { Conversion to open } \\
\text { thoracotomy }\end{array}$ & 3 & 2 & 1 & 0 \\
\hline
\end{tabular}

vessel loop, the repair could be performed with the robotic approach. However, the main PA was not already encircled in most cases, and conversion was needed.

There are a number of mandatory steps for conversion: first, inform the whole staff including the anesthesiologist of the major bleeding so that blood compensation can be started; secondly, before opening the chest, the PAI has to be controlled with a sponge stick using the most posterior arm so that there is enough space to perform anterolateral thoracotomy by removing the other arms or the most anterior arm, or by removing the most anterior arms in order to have enough space to perform postero-lateral

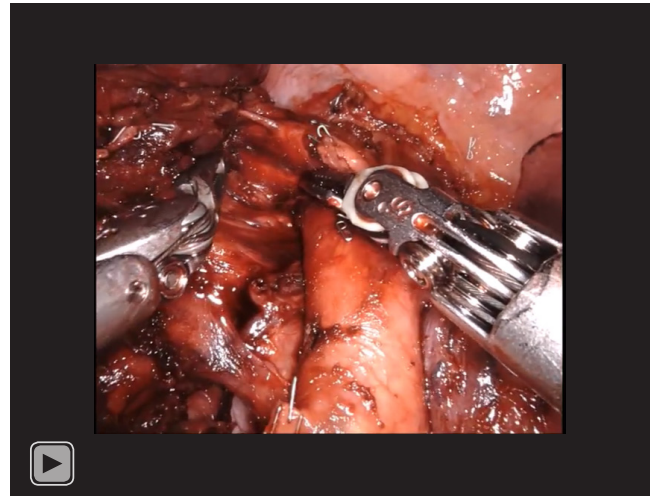

Video 1 Conversion linked to the bleeding of the most distal branches of A1+2 during left upper lobectomy.

thoracotomy; thirdly, the camera should be inserted into the assistant port and maintained throughout the conversion in order to ensure that the bleeding is controlled. In our experience, the main surgeon stays sterile with is gown at the console after the docking of the robot, therefore is case of emergency conversion, the main surgeon just needs to change is gown and gloves. Moreover, in our team, a second surgeon is called to assist with the conversion-it is important to have the assistance of an experienced surgeon in case it is difficult to control the main PA during bleeding.

In this situation, the role of the assistant is major: he had the responsibility to assist the main surgeon by helping him 

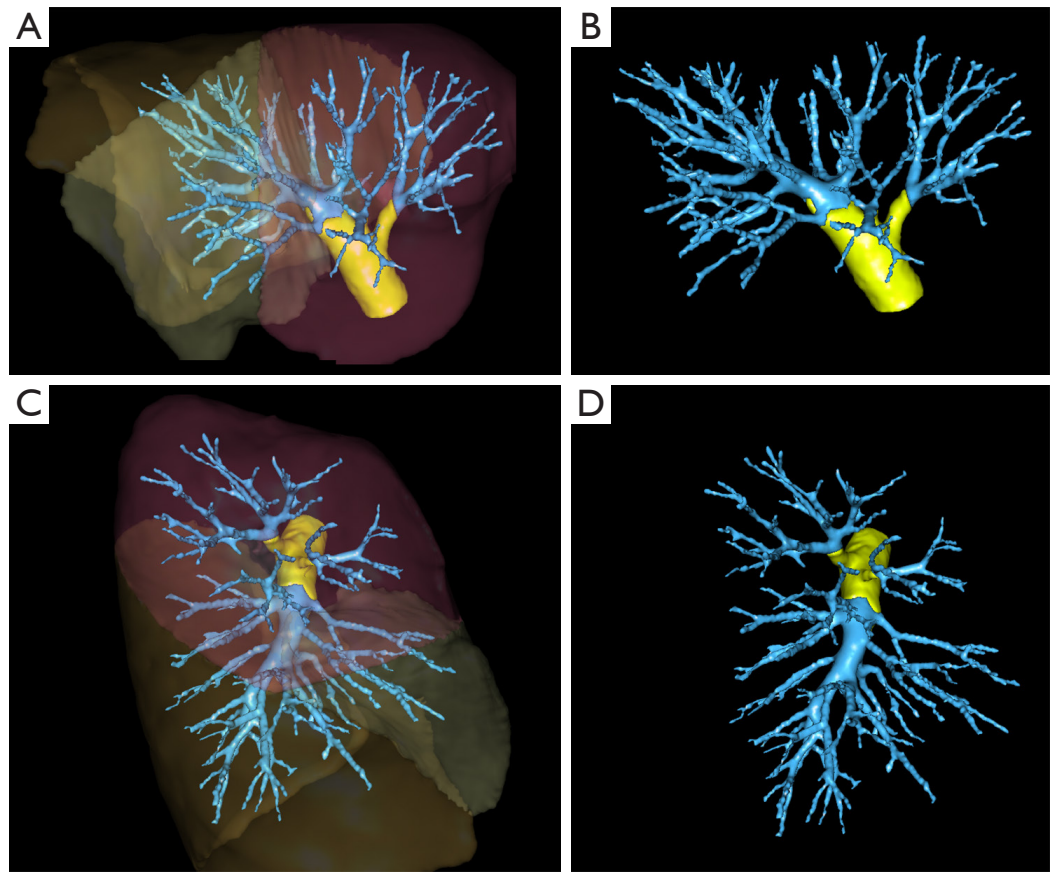

Figure 3 Visualization of the different branches of the right pulmonary artery. (A) represents the frontal view of the right PA with parenchymal division of the right upper, middle and lower lobe; (B) represents the frontal view of the right PA without parenchymal division of the right upper, middle and lower lobe; (C) represents the sagittal view of the right PA with parenchymal division of right upper, middle and lower lobe (D) represents the sagittal view of the right PA without parenchymal division of right upper, middle and lower lobe. The yellow part of the right PA corresponds the injury that couldn't be repaired by robotic way and need emergency conversion. PA, pulmonary artery.

to control the bleeding, by improving exposition, suction, and in case of emergency conversion he is the one who control the bleeding when the main surgeon performs open thoracotomy.

Most of the time, the trocars are inserted in the $7^{\text {th }}$ intercostal, which is too low to perform conversion thoracotomy. After the arms that are not used to compress the PAI are removed, anterolateral or posterolateral thoracotomy has to be performed through the $5^{\text {th }}$ intercostal space so that the main PA can be controlled and clamped. In our experience, posterolateral thoracotomy is a better option for controlling the main PA during major bleeding.

Moreover, the injury of the main PA and the proximal part of the first branches of the PA (yellow part of the PA on Figures 3,4 ) are difficult to repair with a robotic approach even for a skilled surgeon. Indeed, the main PA has to be clamped in order to allow safe repair of the injuries. Therefore, conversion is required to contain the bleeding. The robotic approach should not be used to repair proximal PA due to the risk of an additional accident, especially the risk of tearing the main $\mathrm{PA}$, which would likely lead to poor patient outcomes.

\section{Distal pulmonary artery injury (Videos 2-4; Figures 3,4)}

When injuries occur in the distal part of the PA, especially during middle or lower lobectomies or dissection of the distal branches of the PA for segmentectomies, the bleeding is easier to control, and robotic management is possible (Figures 3,4). In these cases, the PA upstream from the injury can often be clamped with the $4^{\text {th }}$ arm with a smooth forceps, and is then feasible to suture the artery with a robotic approach. In our team, our habits are to use the tip-up forceps (Intuitive surgical SAS, Montrouge, France) because its low strength allows us not to injure the PA, but it is also possible to use bull-dogs to clamp the vessel. This kind of repair should only be conducted in an expert center with a trained team (Videos 2-4). The help of an assistant is critical: in our experience, during major bleeding, the presence of a second skilled surgeon is needed to perform 

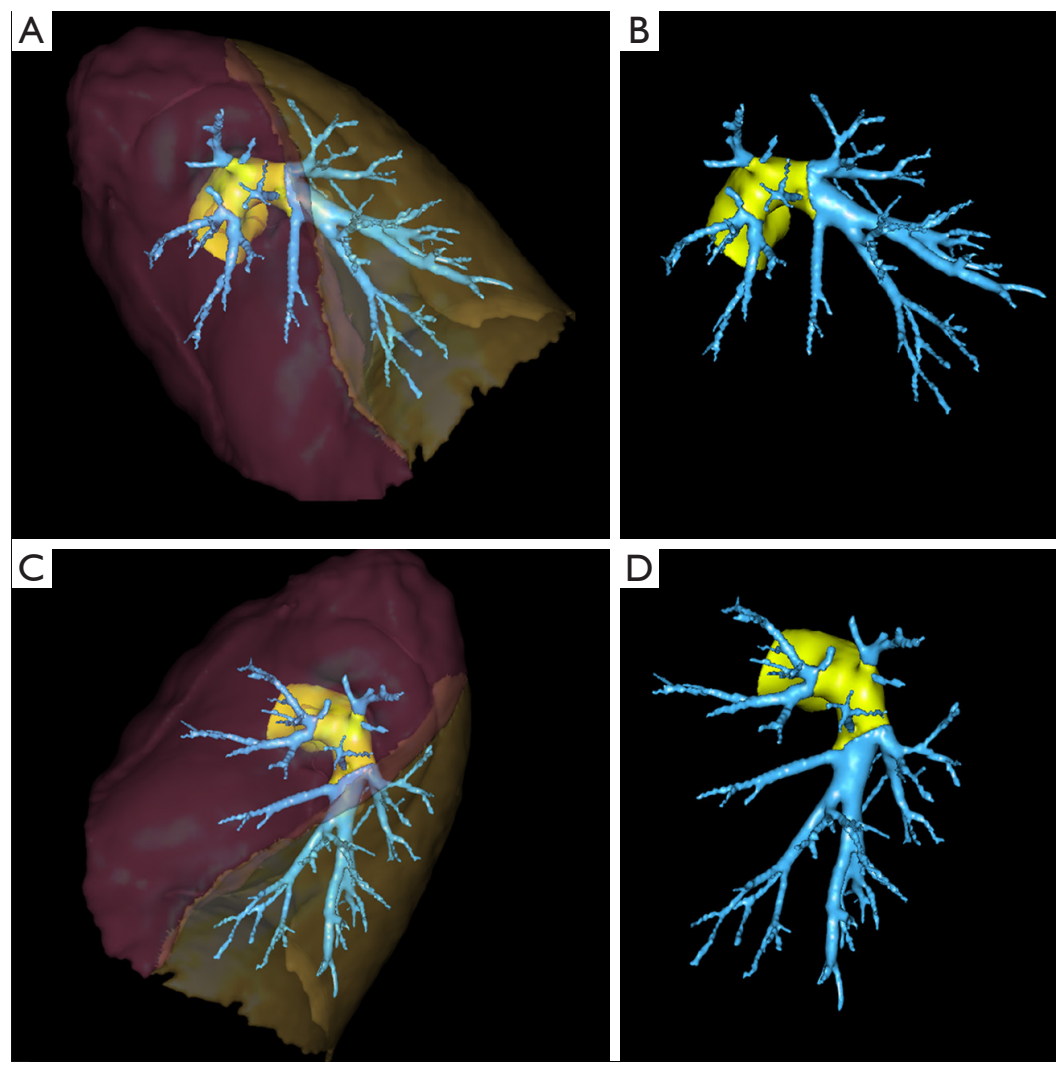

Figure 4 Visualization of the different branches of the left pulmonary artery. (A) represents the frontal view of the left PA with parenchymal division of the left upper and lower lobe; (B) represents the frontal view of the left PA without parenchymal division of the left upper and lower lobe; (C) represents the sagittal view of the left PA with parenchymal division of the left upper and lower lobe; (D) represents the sagittal view of the left PA without parenchymal division of the left upper and lower lobe. The yellow part of the left PA corresponds the injury that couldn't be repaired by robotic way and need emergency conversion. PA, pulmonary artery.

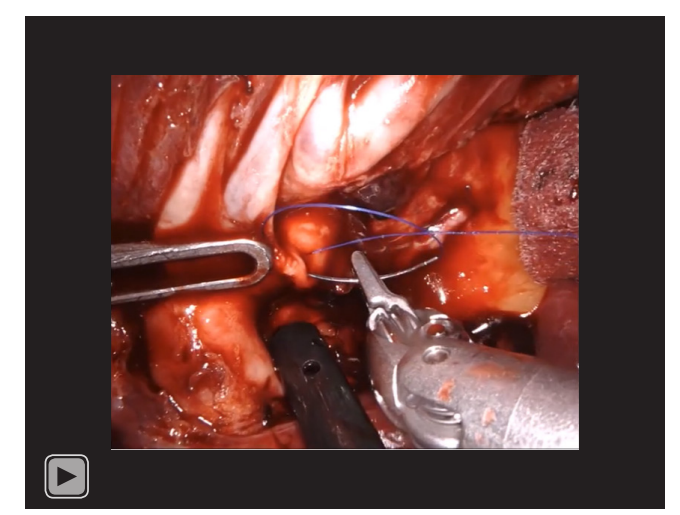

Video 2 Management A5 bleeding during middle lobectomy.

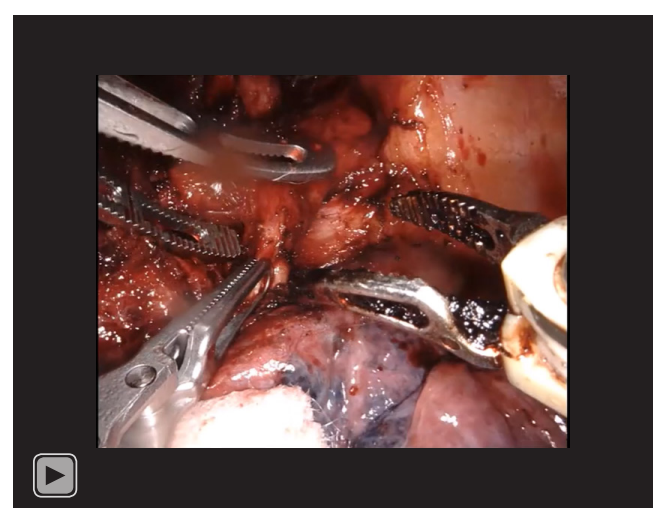

Video 3 Management of A1 a bleeding during right upper S1 segmentectomy. 


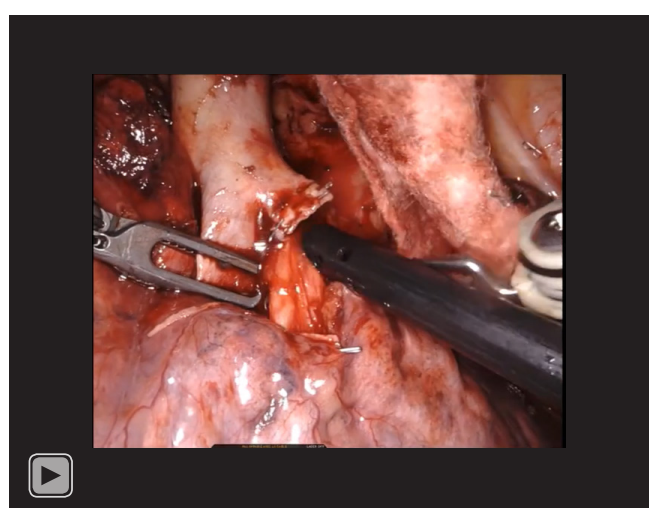

Video 4 Management of A7 bleeding during S7-8 right lower lobe segmentectomy.

suction and to provide adequate exposure for the technical management of the injury.

\section{Prevention of PAI}

Even experienced board-certified thoracic surgeons are subject to major intraoperative incidents (3). In order to minimize the risk of injuries during robotic lung surgery, processes such as simulation, training and preoperative planning using 3 -dimensional imaging can be used.

\section{Simulation}

As previously reported, simulation in surgery has different objectives: acquiring surgical techniques, improving team coordination, and clinical training for the multidisciplinary management of acute surgical emergencies.

Simulation in thoracic surgery is profitable for all practitioners: for resident and younger surgeons it is an opportunity to learn surgical gestures and to dissect the pulmonary hilum; for more experienced surgeons it provides an opportunity to learn how to manage and coordinate a crisis scenario including nursing and anesthesiologist staff.

In cases of PA bleeding, life-saving decisions have to be taken within a very short timeframe. Therefore, training for the management of this risky situation before it arises has major benefits for the entire team. Appropriate decision making, communication, and inter-professional skills are vital for positive patient outcomes in both routine and crisis scenarios $(11,12)$. Before the surgery, the surgeon must prepare by reviewing the scenarios in which emergency conversion should be performed after bleeding control and the injury can be repaired using the robotic approach.
Simulation is a good approach for training both for younger surgeons with less experience and for older surgeons training to use a new technique (13). Over the last decade, many simulators have been created for the purpose of training for open thoracic surgery, VATS and RATS (14-16). Different virtual reality simulators have been developed for VATS lobectomy training, providing a realistic approach to the management of lobectomy that is relevant for all different skill levels (17). Virtual reality simulators have also been developed for RATS; these systems have proven that they are able to improve surgeon efficiency and the quality of learning during mitral surgery or lobectomy $(18,19)$.

Finally, preoperative planning using 3-dimensional imaging could be used to identify the anatomical disposition of the vessels before minimally invasive surgery such VATS or RATS, therefore minimizing the risk of major PA bleeding (20).

\section{Tips and tricks}

In order to prevent vascular injury, there are some rules:

(I) Never forget to keep the vision of your 3 instruments before moving them;

(II) Do not dissect the PA without a good exposure and always keep a gaz sponge close by to compress the PA if necessary;

(III) Control the tension on the tissues by changing the color or brightness of the tissues;

(IV) Do not pull too much on the PA during dissection;

(V) Avoid dissecting the vessels by removing the jaws from the forceps (i.e., Maryland forceps);

(VI) Pay attention if the assistant is manipulating the stapler himself: the outside movement of the most anterior arm of the system could move the stapler outside and thus having the vessels pulled out from the inside at the time of stapling.

\section{Conclusions}

Thoracic surgeons who are not experienced in minimally invasive surgery techniques require specific training in order to develop techniques for conversion and specific strategies to manage major bleeding.

\section{Acknowledgments}

The authors would like to thank Suzanne Rankin (Dijon 
University Hospital) for revising the manuscript. Funding: None.

\section{Footnote}

Provenance and Peer Review: This article was commissioned by the editorial office, Fournal of Visualized Surgery for the series "Robotic Assisted Thoracic Surgery: Advanced Procedures in Lung and Mediastinum: From Postinduction TTT (immunotherapy) to Sleeve Resection, Complex Segmentectomies and Extended Thymectomy for Myasthenia Gravis". The article has undergone external peer review.

Reporting Checklist: The authors have completed the Narrative Review reporting checklist. Available at https:// jovs.amegroups.com/article/view/10.21037/jovs-20-147/rc

Conflicts of Interest: All authors have completed the ICMJE uniform disclosure form (available at https:// jovs.amegroups.com/article/view/10.21037/jovs-20-147/ coif). The series "Robotic Assisted Thoracic Surgery: Advanced Procedures in Lung and Mediastinum: From Post-induction TTT (immunotherapy) to Sleeve Resection, Complex Segmentectomies and Extended Thymectomy for Myasthenia Gravis" was commissioned by the editorial office without any funding or sponsorship. JMB served as the unpaid Guest Editor of the series. PBP reports personal fees from Intuitive Surgical and Medtronic, during the conduct of the study; personal fees from Intuitive Surgical and Medtronic, outside the submitted work. JMB reports personal fees from Intuitive surgical and Medtronic, during the conduct of the study; personal fees from Intuitive surgical and Medtronic, outside the submitted work. The authors have no other conflicts of interest to declare.

Ethical Statement: The authors are accountable for all aspects of the work in ensuring that questions related to the accuracy or integrity of any part of the work are appropriately investigated and resolved. All procedures performed in this study were in accordance with the Helsinki Declaration (as revised in 2013). The manuscript is waived from patient informed consent according to the ethics committee or institutional review board.

Open Access Statement: This is an Open Access article distributed in accordance with the Creative Commons Attribution-NonCommercial-NoDerivs 4.0 International
License (CC BY-NC-ND 4.0), which permits the noncommercial replication and distribution of the article with the strict proviso that no changes or edits are made and the original work is properly cited (including links to both the formal publication through the relevant DOI and the license). See: https://creativecommons.org/licenses/by-nc-nd/4.0/.

\section{References}

1. Flores RM, Ihekweazu U, Dycoco J, et al. Video-assisted thoracoscopic surgery (VATS) lobectomy: catastrophic intraoperative complications. J Thorac Cardiovasc Surg 2011;142:1412-7.

2. Cerfolio RJ, Bess KM, Wei B, et al. Incidence, Results, and Our Current Intraoperative Technique to Control Major Vascular Injuries During Minimally Invasive Robotic Thoracic Surgery. Ann Thorac Surg 2016;102:394-9.

3. Decaluwe H, Petersen RH, Hansen H, et al. ESTS Minimally Invasive Thoracic Surgery Interest Group (MITIG). Major intraoperative complications during video-assisted thoracoscopic anatomical lung resections: an intention-to-treat analysis. Eur J Cardiothorac Surg 2015;48:588-98; discussion 599.

4. Louie BE. Catastrophes and complicated intraoperative events during robotic lung resection. J Vis Surg 2017;3:52.

5. Toker A, Özyurtkan MO, Kaba E, et al. Robotic anatomic lung resections:the initial experience and description of learning in 102 cases. Surg Endosc 2016;30:676-83.

6. Adams RD, Bolton WD, Stephenson JE, et al. Initial multicenter community robotic lobectomy experience: comparisons to a national database. Ann Thorac Surg 2014;97:1893-8; discussion 1899-900.

7. Melfi FM, Fanucchi O, Davini F, et al. Robotic lobectomy for lung cancer: evolution in technique and technology. Eur J Cardiothorac Surg 2014;46:626-30; discussion 630-1.

8. Dylewski MR, Ohaeto AC, Pereira JF. Pulmonary resection using a total endoscopic robotic video-assisted approach. Semin Thorac Cardiovasc Surg 2011;23:36-42.

9. Yang HX, Woo KM, Sima CS, et al. Long-term Survival Based on the Surgical Approach to Lobectomy For Clinical Stage I Nonsmall Cell Lung Cancer: Comparison of Robotic, Video-assisted Thoracic Surgery, and Thoracotomy Lobectomy. Ann Surg 2017;265:431-7.

10. Cao C, Cerfolio RJ, Louie BE, et al. Incidence, Management, and Outcomes of Intraoperative Catastrophes During Robotic Pulmonary Resection. Ann Thorac Surg 2019;108:1498-504.

11. Yule S, Rowley D, Flin R, et al. Experience matters: 
comparing novice and expert ratings of non-technical skills using the NOTSS system. ANZ J Surg 2009;79:154-60.

12. Bierer J, Memu E, Leeper WR, et al. Development of an In Situ Thoracic Surgery Crisis Simulation Focused on Nontechnical Skill Training. Ann Thorac Surg 2018;106:287-292.

13. Villanueva C, Xiong J, Rajput S. Simulation-based surgical education in cardiothoracic training. ANZ J Surg 2020;90:978-83.

14. Carter YM, Marshall MB. Open lobectomy simulator is an effective tool for teaching thoracic surgical skills. Ann Thorac Surg 2009;87:1546-50.

15. Iwasaki A, Moriyama S, Shirakusa T. New trainer for video-assisted thoracic surgery lobectomy. Thorac Cardiovasc Surg 2008;56:32-6.

16. Marshall MB, Wilson BM, Carter YM. Thoracic surgery skill proficiency with chest wall tumor simulator. J. Surg. Res 2012;174:250-6.

doi: 10.21037/jovs-20-147

Cite this article as: Pagès PB, Gutierrez I, Baste JM. Pulmonary artery repair during robotic lung resection: narrative review and management. J Vis Surg 2022;8:3.
17. Jensen K, Bjerrum F, Hansen HJ, et al. A new possibility in thoracoscopic virtual reality simulation training: development and testing of a novel virtual reality simulator for videoassisted thoracoscopic surgery lobectomy. Interact. Cardiovasc Thorac Surg 2015;21:420-6.

18. Valdis M, Chu MW, Schlachta CM, et al. Validation of a Novel Virtual Reality Training Curriculum for Robotic Cardiac Surgery: A Randomized Trial. Innovations (Phila) 2015;10:383-8.

19. Valdis M, Chu MW, Schlachta C, Kiaii B. Evaluation of robotic cardiac surgery simulation training: a randomized controlled trial. J. Thorac Cardiovasc Surg 2016;151:1498505.e2.

20. Le Moal J, Peillon C, Dacher JN, Baste JM. Threedimensional computed tomography reconstruction for operative planning in robotic surgery: a pilot study. J Thorac Dis 2018;10:196-201. 